Esta revista forma parte del acervo de la Biblioteca Jurídica Virtual del Instituto de Investigaciones Jurídicas de la UNAM

\title{
Responsabilidad penal internacional: \\ los nuevos escenarios dogmáticos
}

\author{
International Criminal Responsibility: \\ The New Dogmatic Scenarios
}

Responsabilité pénale internationale:

les nouveaux scenarios dogmatiques

Javier Dondé Matute*

SUMARIO: I. Introducción. II. El precedente de Núremberg. III. Responsabilidad penal internacional y su distinción con la responsabilidad estatal. IV. Responsabilidad penal internacional y su distinción con la responsabilidad penal nacional.V. Responsabilidad grupal. VI. Culpabilidad.

VII. Normas de interpretación. VIII. Conclusión. IX. Bibliografía.

* Doctor en derecho penal internacional y comparado por la Universidad de Aberdeen, Escocia; profesor-investigador titular "C" del Inacipe; miembor del Sistema Nacional de Investigadores nivel II.

Artículo recibido el 11 de mayo de 2017 Aprobado para publicación el 25 de septiembre de 2017 
RESUMEN: El objetivo de este estudio es establecer los alcances y límites de la responsabilidad penal internacional. Este concepto es la piedra angular del derecho penal internacional, del cual se desprenden otros principios generales y las normas del sistema del Estatuto de la Corte Penal Internacional. Se trata de un principio que surgió históricamente en la Carta y la sentencia de Núremberg. Asimismo, sus características lo distinguen de la responsabilidad estatal y de la responsabilidad penal nacional. En particular, es importante mencionar el carácter grupal de esta responsabilidad, así como el reconocimiento de individualidad de las personas que cometen crímenes internacionales, a través del principio de culpabilidad.

Palabras clave: Corte Penal Internacional, responsabilidad penal internacional, dogmática penal.

ABSTRACT: The aim of this article is to establish the reach of international criminal responsibility. It is argued that it is a founding principle of International Criminal Law, and the origin of other general principles and rules in the Statute of the International Criminal Court. It is a historic principle that came about from the Nuremberg Charter and the judgment of the International Military Court. International criminal responsibility has its own features, which set it apart from state responsibility and criminal responsibility in national jurisdictions. Specifically, it is a group responsibility, but it also recognized the individuality of the persons by way of the principle of culpability or blameworthiness.

Key words: International Criminal Court, international criminal responsability, criminal legal theory.

RÉSUMÉ: Le but del article est d'éstablir la portée et les limites de la responsabilité pénale internationale. Cette concept est la pierre angulaire du droit pénal international, où ils émergent autres principes généraux et les règles du système du Statut de Rome de la Cour Pénale Internationale. Historiquement il s'agit d'un príncipe qui né de la Charte et le Jugement de Nuremberg. Aussi, ses caractéristiques le distinguent des la responsabilité des états et la responsabilité pénale nationale. Il est notamment mentionner le caractère du groupe de cette responsabilité ainsi que la reconnaissance de l'individualité des personnes qui commettent des crimes internationaux, par le príncipe de la culpabilité.

Mots-clés: Cour Pénale Internationale, responsabilité pénale internationale, dogmatique criminelle. 
Esta revista forma parte del acervo de la Biblioteca Jurídica Virtual del Instituto de Investigaciones Jurídicas de la UNAM

\section{INTRODUCCIÓN}

El concepto de responsabilidad penal internacional es lo que hace posible que exista el derecho penal internacional (DPI). La posibilidad de imputar directamente a los individuos su responsabilidad por violaciones al derecho internacional es lo que hace necesario preguntarse por cuáles conductas y bajo qué circunstancias ocurren. Estas dudas las resuelve en el ámbito nacional el derecho penal y en el ámbito internacional el DPI. Como se trata del comienzo de todos los cuestionamientos del DPI puede decirse que es el principio fundador de esta rama del derecho.

Todas las normas de DPI instauran las condiciones para establecer la responsabilidad penal internacional y, a su vez, la esta última establece las condiciones en virtud de las cuales las normas de DPI existen.

En el presente artículo se desarrollarán las siguientes argumentaciones para sustentar dicha afirmación. Primeramente, se demostrará que la responsabilidad penal internacional surgió en Núremberg y creó la necesidad de generar normas del DPI. Este nuevo concepto se puede distinguir, por un lado, de la responsabilidad estatal y, por otro, de la responsabilidad penal nacional. Hechas estas distinciones se explicarán las características de la responsabilidad penal internacional; en primer lugar, desde una perspectiva formal y material, y, en segundo, describiendo los elementos que la componen; principalmente, su carácter grupal y el reconocimiento de la culpabilidad.

\section{EL PRECEDENTE DE NÚREMBERG}

ElTribunal de Núremberg y la sentencia que consecuentemente se emitió, ${ }^{1}$ pueden ser criticados por varios motivos. ${ }^{2}$ Sin embargo, lo que es incues-

1 Tribunal Militar Internacional de Núremberg, Judgment in the Trial of German Major War Criminals, 1 de octubre de 1946.

2 Entre los argumentos más frecuentes en contra de este Tribunal están la violación al principio de legalidad penal, el hecho de constitución de un tribunal especial y que representa la justicia de los vencedores en la Segunda Guerra Mundial.Véase Tomuschat, Christian, "The Legacy of Nuremberg”, Journal of International Criminal Justice, vol. 4, núm. 4, 2006, pp. 830-844. 
Esta revista forma parte del acervo de la Biblioteca Jurídica Virtual del Instituto de Investigaciones Jurídicas de la UNAM

tionable es que constituyó el fundamento jurídico en virtud del cual se crea la responsabilidad penal internacional. Si bien con anterioridad se habían establecido intentos para procesar internacionalmente a ciertos individuos, principalmente presuntos criminales de guerra, ${ }^{3}$ ninguno de ellos tuvo la inercia necesaria para provocar el desarrollo del DPI, tal y como lo tuvo el precedente de Núremberg. Así pues, resulta de vital importancia establecer cuál fue el razonamiento que condujo a los jueces de dicho tribunal a sostener que existe la responsabilidad penal internacional.

De inicio es importante mencionar que la responsabilidad penal internacional surge de la discusión sobre la existencia de crímenes contra la paz previos a la elaboración de la Carta del Tribunal de Núremberg ${ }^{4}$. La sentencia comienza por enfatizar que el Tribunal tiene competencia para conocer de la posible comisión de crímenes contra la paz; dado que la Carta así lo específica y dado que el Tribunal tiene como mandato cumplir con la Carta, no está facultado para cuestionar la competencia que la misma le otorga. Sin embargo, los jueces se vieron en la necesidad de resolver el problema de la posible aplicación retroactiva de las disposiciones de la Carta. Es en este contexto que se pronuncia en relación a la responsabilidad penal internacional, ya que para resolver lo concerniente a la aplicación retroactiva de las conductas, había que determinar, en primer lugar, si eran ilícitos penales con anterioridad a la emisión de dicho documento.

En este contexto, el Tribunal advirtió que, por lo menos, desde la firma del Tratado de París de 1928, también conocido como Pacto BriandKellogg, se renunció a la guerra como un instrumento de política nacional y como un mecanismo de resolución de controversias entre Estados. Por lo tanto, iniciar una guerra de agresión constituía un ilícito internacional a partir de ese momento. A pesar de ello, como se reconoce en la propia sentencia, un ilícito internacional no constituye en sí mismo un crimen internacional.

No obstante, la sentencia indica que a diferencia de los sistemas nacionales, el derecho internacional no cuenta con legislaturas, por lo que en

3 Véase Greppi, Edoardo, "La evolución de la responsabilidad penal individual bajo el derecho internacional”, Revista Internacional de la Cruz Roja, núm. 835, 1999, disponible en: www.icrc.org/web/spa/sitespa0.nsf/htmlall/5tdnnf?opendocument.

4 Lo analizado en este apartado corresponde a la sección de la resolución denominada "The Law of the Charter" (Derecho de la Carta) en Tribunal Militar Internacional de Núremberg, Judgment in the Trial of German MajorWar Criminals, 1 de octubre de 1946. 
Esta revista forma parte del acervo de la Biblioteca Jurídica Virtual del Instituto de Investigaciones Jurídicas de la UNAM

los convenios internacionales se deben de prescribir solamente principios generales y no cuestiones administrativas de procedimiento. Así, el Pacto debe interpretarse en el contexto de la costumbre internacional, la cual representa el dinamismo de esta rama jurídica. En este contexto, debe entenderse que la prohibición contenida en el Pacto de París ha evolucionado para ser conocida como un crimen internacional. Para fundamentar su argumento, el Tribunal señaló los siguientes antecedentes, en los que se menciona expresamente que la agresión es un delito internacional:

- El proyecto de Tratado de Asistencia Mutua de la Liga de las Naciones de 1923.

- El preámbulo al Protocolo para la Resolución Pacífica de Disputas Internacionales de 1926 (Protocolo de Ginebra). El propio Tribunal acepta que dicho Protocolo no fue ratificado.

- La resolución que por unanimidad se adoptó en la Sexta Conferencia Pan-Americana de La Habana, el 18 de febrero de 1928 por veintiún repúblicas del continente.

- Los artículos 227 y 228 del Tratado de París que ordenaba enjuiciar al Kaiser Guillermo II por violar "la moral internacional y la santidad de los tratados".

El resto de la argumentación sobre este punto descansa sobre la posibilidad de establecer responsabilidad penal internacional a los Jefes de Estado. Toda vez que éste es un tema diverso, y que de hecho ya presupone la existencia de esta responsabilidad, en términos generales, ya no es parte de la presente discusión.

Existe un inconveniente esencial con la resolución de Núremberg acerca de este tema, y es que da un paso lógico entre los ilícitos internacionales y los crímenes internacionales que no estuvo fundado adecuadamente. Como se puede observar, los cuatro instrumentos internacionales que se mencionan no parecen ser idóneos para comprobar la existencia de un delito de agresión, pues los dos primeros no son documentos terminados que conformen una aceptación general; el tercero es un documento regional y, aun así, se encuentra limitado por la aceptación de sólo veintiún Estados; en tanto que en el cuarto la disposición penal que incluye se limita a un individuo, por actos cuya criminalidad es cuestionable, aunque no así su ilegalidad. 
Esta revista forma parte del acervo de la Biblioteca Jurídica Virtual del Instituto de Investigaciones Jurídicas de la UNAM

Independientemente de lo anterior, el Tribunal llegó a la conclusión de que estos precedentes eran suficientes para establecer la existencia previa de la responsabilidad penal internacional por crímenes contra la paz.

De esta forma, el Tribunal de Núremberg, en su argumentación, confunde la diferencia entre responsabilidad estatal y responsabilidad penal internacional, de tal manera que termina justificando la eficacia del derecho internacional, a través de la sanción penal al concluir que "los crímenes contra el derecho internacional son cometidos por hombres, no entidades abstractas, y solamente sancionando a los individuos que cometen estos crímenes pueden hacerse cumplir las disposiciones del derecho internacional". ${ }^{5}$

Como se mencionó, en realidad no parece haber un fundamento para que el Tribunal de Núremberg llegara a la conclusión de la preexistencia de la responsabilidad penal internacional; sin embargo, a futuro, esta sentencia constituyó el precedente y fundamento para establecer la existencia de este concepto básico del DPI.

La fragilidad de la argumentación y de la legitimidad del Tribunal, así como sus determinaciones fueron la razón por la cual la Asamblea General de las Naciones Unidas tuvo que ratificar los principios que se deducen de la experiencia de Núremberg, de su Carta y de sus resoluciones, en virtud de la resolución 95(I) del 11 de diciembre de $1946 .{ }^{6}$

Posteriormente, la Asamblea General solicitó, en virtud de la resolución 177(II), a la Comisión de Derecho Internacional que codificara dichos Principios. En resumen, estos Principios establecen el reconocimiento de la responsabilidad penal internacional y las condiciones básicas para el establecimiento de la misma, tal y como se explicó en la introducción a este estudio.

En dicha resolución se señaló que cualquier persona que comete un acto que constituye un crimen según el derecho internacional es responsable y puede ser penado (Principio I). Asimismo, se consideran crímenes según el derecho internacional los atentados contra la paz, los crímenes de lesa

5 Tribunal Militar Internacional de Núremberg, Judgment in the Trial of German Major War Criminals, 1 de octubre de 1946, p. 55.

6 CIJ, Case Concerning the Application of the Convention on the Prevention and Punishment of the Crime of Genocide (Bosnia-Herzegovina v. Serbia and Montenegro), Judgment, I.C.J. Reports 2007, 26 February 2007, p. 43, párr. 172. Reconociendo que el origen de la responsabilidad penal internacional se encuentra en Núremberg. 
Esta revista forma parte del acervo de la Biblioteca Jurídica Virtual del Instituto de Investigaciones Jurídicas de la UNAM

humanidad y los crímenes de guerra (Principio VI). Esta responsabilidad incluye la complicidad en la comisión de estos crímenes (Principio VII).

La responsabilidad penal internacional no está condicionada a que dicha conducta esté tipificada y penada de conformidad con el derecho interno (Principio II), a que la persona sea jefe de Estado o funcionario público (Principio III) o a que haya actuado de conformidad con las órdenes de un superior jerárquico (Principio IV).

Por otro lado, toda persona acusada de un crimen de conformidad con el derecho internacional tiene derecho a un juicio imparcial (Principio V).

Dichos principios son la base del DPI y a lo largo de su desarrollo se han ampliado, modificado y complementado con otros principios, pero incluso instrumentos internacionales tan complejos como el Estatuto de la Corte Penal Internacional (ECPI) parten de esta base, establecida hace 60 años. ${ }^{7}$

A pesar de que los inicios del DPI fueron erráticos, el concepto de responsabilidad penal internacional ya no está sujeto a discusión. En todo caso, las condiciones para establecer dicha responsabilidad siguen abiertas a la crítica, aunque debe considerarse que éste es el proceso natural de evolución que podemos esperar de dicha rama del derecho internacional.

\section{RESPONSABILIDAD PENAL INTERNACIONAL Y SU DISTINCIÓN CON LA RESPONSABILIDAD ESTATAL}

Es importante señalar el fundamento de la responsabilidad penal internacional como el primero y más importante principio del DPI. Para poder establecer la existencia de una responsabilidad (penal) para los individuos es necesario superar la noción clásica de que solamente los Estados y las organizaciones internacionales son sujetos de derecho en el ámbito internacional. Aunque esta afirmación sigue siendo cierta, en la actualidad debe ser matizada. Existen dos ámbitos en los cuales esta regla admite excepciones: el derecho internacional de los derechos humanos y el DPI. ${ }^{8}$

7 Sobre la evolución y vigencia de los principios de Núremberg véase Dondé Matute, Javier (coord.), Principios de Núremberg: Desarrollo y Actualidad, México, Inacipe, 2015.

8 Cfr. Ratner, Steven R. y Abrams, Jason S., Accountability for Human Rights Atrocities in International Law. Beyond the Nuremberg Legacy, 2a ed., Nueva York, Oxford University Press, 2001, pp. 10 y ss. Pudiera incluirse en este grupo al derecho internacional humanitario, sin 
Esta revista forma parte del acervo de la Biblioteca Jurídica Virtual del Instituto de Investigaciones Jurídicas de la UNAM

En el derecho internacional de los derechos humanos, si bien tanto los tratados internacionales como la Convención Americana sobre Derechos Humanos y la Convención Europea de los Derechos Humanos, están dirigidos a los Estados (cuya obligación consiste en respetar y hacer respetar los derechos y libertades consagrados en estos instrumentos internacionales en su ámbito interno y jurisdiccional); los individuos tienen la posibilidad de accionar las instancias establecidas para hacer efectivos sus derechos derivados de los tratados y hacer cumplir las obligaciones estatales. En otras palabras, se les otorga una acción procesal ante la Comisión Interamericana de Derechos Humanos y la Corte Europea de Derechos Humanos, respectivamente.

En el DPI sucede algo similar, para poder afirmar que los individuos tienen una responsabilidad (penal) internacional por violaciones al derecho internacional es necesario establecer, como una premisa, el reconocimiento de la personalidad jurídica de los individuos. Esto ya ha sido determinado, pues, en la actualidad, no existe ningún tipo de controversia sobre el reconocimiento del individuo como sujeto del derecho internacional. ${ }^{9}$

Es importante hacer una distinción entre la responsabilidad estatal internacional y la responsabilidad penal internacional. La primera es la obligación que tiene un Estado con respecto a otro de responder mediante una reparación adecuada por la violación de una regla del derecho internacional. ${ }^{10}$ Es preciso aclarar que este tipo de responsabilidad únicamente se da entre Estados. Por su parte, la responsabilidad penal internacional es la obligación de los individuos de responder, mediante una pena y resarcimiento de los daños causados, por los crímenes internacionales que hayan cometido. ${ }^{11}$ En

embargo, no hay un reconocimiento del individuo como sujeto de alguna acción procesal o como responsable por la violación de alguna obligación internacional, como en las otras ramas del derecho internacional. En todo caso, una violación al derecho internacional humanitario puede tomar la forma de una violación de derechos humanos o de un crimen de guerra, en cuyo caso serán aplicables las mismas reflexiones expresadas en el cuerpo de este apartado.

9 Véase Shaw, Malcolm N., International Law, 5a ed., Reino Unido, Oxford University Press, 2003; Herdegen, Matthias, Derecho internacional público, trad. de Marcela Anzola, México, UNAM-Fundación Konrad Adenauer, 2005.

10 Comisión de Derecho Internacional, Draft articles on Responsibility of States for InternationallyWrongful Acts, with commentaries, 2001, art. 1, commentary 1 and 3.

11 Véase también, CIJ, Case Concerning the Application of the Convention on the Prevention and Punishment of the Crime of Genocide (Croatia v. Serbia), Judgment, 3 February 2015, párr. 129. 
Esta revista forma parte del acervo de la Biblioteca Jurídica Virtual del Instituto de Investigaciones Jurídicas de la UNAM

resumen, la responsabilidad internacional recae en los Estados y la responsabilidad penal internacional en los individuos.

Un aspecto importante de la responsabilidad internacional, ya sea estatal o individual, es que no son mutuamente excluyentes. Una misma conducta puede caracterizarse como una violación al derecho internacional o como una violación a los derechos humanos, en ambos casos resultaría en responsabilidad estatal. Adicionalmente, la persona física que haya realizado la conducta en concreto puede ser penalmente responsable en el ámbito internacional, de conformidad con las normas de autoría y participación aplicables (incluyendo lo relativo a la responsabilidad del superior jerárquico).

Dicha posibilidad fue reconocida por la Corte Internacional de Justicia en el caso Bosnia-Herzegovina v. Serbia-Montenegro, ${ }^{12}$ en virtud de la cual se estableció que aunque la Convención para Prevenir y Sancionar el Crimen de Genocidio está diseñada para establecer la responsabilidad penal internacional del individuo, por la comisión de dicho crimen, el Estado también puede ser sujeto de responsabilidad por la comisión del mismo.

Adicionalmente, es importante señalar que el ECPI admite la misma posibilidad al señalar, en su artículo 25(4), que "nada de lo dispuesto en el presente Estatuto respecto de la responsabilidad penal de las personas naturales afectará a la responsabilidad del Estado conforme al derecho internacional". ${ }^{13}$

Por último, en los párrafos 5 y 6 del preámbulo del ECPI se reconoce la responsabilidad penal internacional. Igualmente, se reconoce en el artículo 1, ya que se indica que la Corte "estará facultada para ejercer su jurisdicción sobre personas respecto de los crímenes más graves”. En el mismo sentido, el artículo 25 indica que "la Corte tendrá competencia respecto de las personas naturales".

Por lo que se ha dicho hasta este momento, existen dos tipos de responsabilidad en el ámbito internacional, incluso por los mismos hechos. Por ejemplo, un Estado que es condenado por cometer actos de tortura tendrá

12 CIJ, Case Concerning the Application of the Convention on the Prevention and Punishment of the Crime of Genocide (Bosnia-Herzegovina v. Yugoslavia), Preliminary Objections, Judgment, I.C.J. Reports 1996, p. 595, 11 July 1996, párr. 32.

13 Véase también, CIJ, Case Concerning the Application of the Convention on the Prevention and Punishment of the Crime of Genocide (Bosnia-Herzegovina v. Serbia and Montenegro), Judgment, I.C.J. Reports, p. 43, 26 February 2007, párr. 173. En esta parte de la Sentencia de fondo se reconoce con base en el propio artículo 25 del ECPI que hay una responsabilidad dual en el derecho internacional. 
Esta revista forma parte del acervo de la Biblioteca Jurídica Virtual del Instituto de Investigaciones Jurídicas de la UNAM

una responsabilidad internacional. Por su parte, los funcionarios que cometen dichos actos también pueden estar realizando crímenes de lesa humanidad o crímenes de guerra; sin que sean mutuamente excluyentes.

Sin embargo, hay otro tipo de distinciones importantes. Quizá el aspecto que más "humaniza" a la responsabilidad penal internacional es la importancia de considerar la conducta ilegal como una conducta que exige un elemento subjetivo, para evitar la responsabilidad objetiva (strict liability) ${ }^{14}$ Dicho elemento es uno de los principios del DPI. Derivado de lo anterior, también es importante destacar que la responsabilidad penal internacional exige un componente adicional que es la culpabilidad. Más adelante se argumentará que la culpabilidad es una de las características de esta responsabilidad, pero antes es importante distinguirla de la responsabilidad penal nacional.

\section{RESPONSABILIDAD PENAL INTERNACIONAL Y SU DISTINCIÓN CON LA RESPONSABILIDAD PENAL NACIONAL}

La distinción entre estos dos tipos de responsabilidad penal se da en diversos niveles. En un plano formal, puede decirse que la responsabilidad penal internacional tiene como fuentes los tratados internacionales y demás fuentes del derecho internacional o, más concretamente, del DPI. Sin embargo, el artículo 21 del ECPI prevé como fuentes del DPI normas, o por lo menos principios generales de los sistemas jurídicos del mundo. ${ }^{15}$ Aunque la fórmula que se emplea es de una fuente supletoria, parece que la distinción formal no es del todo precisa.

14 Véase Comisión de Derecho Internacional, Draft articles on Responsibility of States for Internationally Wrongful Acts, with commentaries, 2001, art. 2, commentary 10. Para que haya responsabilidad internacional de los Estados solamente es necesario establecer dos elementos: la atribución al Estado de la conducta y la violación de una obligación de derecho internacional. En los comentarios se aclara que ninguno de estos dos elementos incluye un elemento subjetivo. En este caso se analiza el elemento subjetivo del genocidio, aunque esto es debido al hecho de que se trata de un dolo específico, esencial para la definición del crimen en cuestión.

15 Véase ECPI, art 21(1)(c) "En su defecto, los principios generales del derecho que derive la Corte del derecho interno de los sistemas jurídicos del mundo, incluido, cuando proceda, el derecho interno de los Estados que normalmente ejercerían jurisdicción sobre el crimen, siempre que esos principios no sean incompatibles con el presente Estatuto ni con el derecho internacional ni las normas y estándares internacionalmente reconocidos". 
Esta revista forma parte del acervo de la Biblioteca Jurídica Virtual del Instituto de Investigaciones Jurídicas de la UNAM

Otro criterio que se puede emplear es el bien jurídico tutelado. En otro estudio hice la distinción entre bienes jurídicos nacionales y bienes jurídicos en el ámbito internacional. Asimismo, señalaba que estos últimos pueden desprenderse de los derechos humanos internacionalmente reconocidos, de la Carta de las Naciones Unidas, del ius cogens o de los propios tratados del DPI que, de forma novedosa, reconocen y tutelan bienes jurídicos. ${ }^{16}$

Así, en la medida en la que el origen del bien jurídico sea internacional podemos hablar de crímenes internacionales, mientras que los delitos protegen bienes jurídicos reconocidos en cada Estado. Aunque esta distinción es de corte material, solamente permite distinguir entre crímenes internacionales y delitos; no entre las diferentes formas de responsabilidad penal.

Bassiouni, sin embargo, considera que la diferencia entre ambos tipos de responsabilidad está claramente establecida en el ECPI. Los artículos del 25 a 28 contienen normas jurídicas que establecen la responsabilidad penal internacional y que difieren sustancialmente de lo que se encuentra en cualquier sistema jurídico-penal nacional. Así, las formas de autoría, la exclusión de responsabilidad de menores de 18 años de edad, la irrelevancia del cargo oficial para establecer responsabilidad penal internacional y la responsabilidad del superior jerárquico son facetas propias del DPI que ayudan a distinguir entre ambos tipos de responsabilidad. ${ }^{17}$

Aunque las afirmaciones de Bassiouni ayudarían a consolidar el argumento de distinción que se expone, se debe reconocer un matiz. El artículo 25 del ECPI prevé formas de autoría como la autoría material, la coautoría y la autoría mediata que difícilmente están ausentes del derecho penal nacional. Igualmente, en varios países, a las personas menores de edad no se les aplica el derecho penal. ${ }^{18}$ El cargo oficial no siempre es un obstáculo para llevar a cabo una investigación penal, aunque puede estar sujeta a procedimientos especiales como el desafuero. ${ }^{19}$

Lo que es rescatable del comentario de Bassiouni es que se pueden distinguir formas de autoría que son propias del DPI y que no tienen un referente en el derecho penal nacional. Los casos que destacan son "la comisión

16 Véase Dondé Matute, Javier, Tipos penales en el ámbito internacional, 2a. ed., México, Inacipe, 2012, pp. 21-39.

17 Bassiouni, Cherif M., Crimes against humanity in International Criminal Law, 2a. ed., La Haya, Kluwer Law International, 1999, pp. 370-373.

18 Véase Convención de los Derechos del Niño, art. 40.

19 Véase Constitución Política de los Estados Unidos Mexicanos, art. 111. 
Esta revista forma parte del acervo de la Biblioteca Jurídica Virtual del Instituto de Investigaciones Jurídicas de la UNAM

o tentativa de comisión del crimen por un grupo de personas que tengan una finalidad común" ${ }^{20}$ y la responsabilidad del superior jerárquico. ${ }^{21}$

Estas dos formas de autoría propias del DPI, a su vez tienen en común que implican una responsabilidad grupal. La segunda se abordará en el apartado siguiente; de momento basta con señalar que hay varios autores que enfatizan el hecho de que la diferencia entre el DPI y el derecho penal nacional deriva en el carácter grupal de las comisiones. Ohlin señala dos diferencias: en los crímenes internacionales normalmente participa una pluralidad de personas y la persona que controla el crimen internacional normalmente no lo ejecuta, como sí sucede en los sistemas jurídico-penales nacionales. ${ }^{22}$ Por las mismas razones, Drumbl y Osiel señalan que la criminalidad internacional supera los contornos de responsabilidad del derecho penal (liberal) que predomina internamente. ${ }^{23}$

Consecuentemente, por lo menos desde la perspectiva del bien jurídico tutelado y de la responsabilidad grupal, se pueden marcar claras diferencias entre las responsabilidades penal internacional y penal nacional. En el siguiente apartado se explorará la responsabilidad grupal.

\section{RESPONSABILIDAD GRUPAL}

La postura que se defenderá en este apartado es que la responsabilidad penal internacional es una responsabilidad grupal; es decir, que aunque la imputación (y eventual sentencia) es en contra de una persona, las conductas siempre se cometen con la participación de un grupo; en otras palabras, nunca de forma aislada.

El concepto de responsabilidad grupal no es novedoso en el DPI, ya muchos autores han hecho notar esta característica, aunque desde enfoques distintos. Entre las posturas que se han estudiado vale la pena para el presente estudio señalar que hay autores que destacan la tensión que existe en-

20 Véase ECPI, art. 25 (3) (d).

21 Ibidem, art. 28.

22 Véase Ohlin, Jens David, “Co-Perpetration German Dogmatik or German Invasion?", The Law and Practice of the International Criminal Court: A Critical Account of Challenges and Achievements, Cornell Legal Studies Research Paper No. 14-07, 2015, p. 6.

23 Véase Robinson, Darryl, "International Criminal Law as Justice", Journal of International Criminal Justice, vol. 11, September 2013, p. 702. 
Esta revista forma parte del acervo de la Biblioteca Jurídica Virtual del Instituto de Investigaciones Jurídicas de la UNAM

tre el liberalismo propio del derecho penal occidental, que exige sancionar penalmente sólo a los individuos. ${ }^{24}$ Esto, como se verá más adelante, genera el problema de determinar si la culpabilidad, y en su caso qué concepto de culpabilidad, forma parte de la responsabilidad penal internacional y, por ende, del DPI; esto se explorará en el siguiente apartado.

Para comprobar esta característica de dicha responsabilidad se analizarán las formas de autoría empleadas por la Corte Penal Internacional (CPI), con lo que se evidenciará que aunque la acusación va dirigida a una persona, siempre se realiza considerando su participación en un grupo. No es el momento para hacer una evaluación exhaustiva de las formas de autoría en el DPI, solamente se destacará el elemento grupal en cada una de ellas. ${ }^{25}$ Esta postura encuentra un sustento adicional en el contexto de violencia masiva.

Desde la sentencia del Tribunal de Núremberg se pueden encontrar indicios de la importancia de la responsabilidad grupal en el DPI. La Carta del Tribunal de Núremberg establecía la posibilidad de procesar a las personas que fueran miembros de una organización ilegal. ${ }^{26}$

Esta noción adquirió más fuerza en el Tribunal Penal Internacional para la ex Yugoslavia (TPIY) al crear la empresa criminal conjunta como una nueva forma de autoría. La jurisprudencia la ha dividido en tres categorías. En la primera, los coperpetradores actúan conforme a un plan común con la misma intención criminal. Así, las personas que no llevan a cabo materialmente la conducta criminal (asesinar, violar, torturar) son penalmente responsables si participan voluntariamente del plan común cuando, aunque no realicen

24 Véase Fletcher, George P., “Collective Guilt and Collective Punishment”, Theoretical Inquiries, vol. 5, 2004, pp. 163-178 (aceptando que existe el concepto de culpa colectiva "collective guilt" aunque esto derivaría en sanciones colectivas); Ambos, Kai, Fundamentos de la imputación en el derecho internacional penal, México, Porrúa, 2009, pp. 69 y 70 (existe una doble perspectiva en la imputación penal internacional: el "contexto colectivo de comisión" y la "tradicional imputación individual”); Osiel, Mark, "Banality of Good: Aligning Incentives against Mass Atrocity”, Columbia Law Review, vol. 105, 2005, pp. 1751-1862 (explicando el fenómeno de las atrocidades masivas "mass atrocity" frente el derecho penal y a la responsabilidad individual); Robinson, Darryl, op. cit., p. 705; Stephens, Pamela J., "Collective Criminality and Individual Responsibility: The Constraints of Interpretation”, Vermont Law School Paper, núm. 10-14, 2014.

25 Véase Drumbl, Mark A., "Collective Violence and Individual Punishment: The Criminality of Mass Atrocity”, Northwestern University Law Review, vol. 99, núm. 2, 2005, pp. 39 y 40 (La tensión que existe entre la responsabilidad individual y la responsabilidad grupal ha generado figuras como la empresa criminal conjunta, la responsabilidad de mando y la complicidad "aiding and abetting").

26 Véase Carta del Tribunal de Núremberg, arts. 9-11. 
Esta revista forma parte del acervo de la Biblioteca Jurídica Virtual del Instituto de Investigaciones Jurídicas de la UNAM http://www.juridicas.unam.mx/ https://biblio.juridicas.unam.mx/bjv https://revistas.juridicas.unam.mx/ DOI: http://dx.doi.org/10.22201/iij.24487872e.2018.18.12107

materialmente la conducta, la pretendan. ${ }^{27}$ La segunda es la llamada empresa criminal conjunta sistémica, en ella concurren los elementos de la básica; sin embargo, el plan común se manifiesta a través de un "sistema de represión". ${ }^{28}$ Por lo tanto, la persona debe saber que existe dicho sistema y que participa del mismo. ${ }^{29}$ La tercera es la llamada empresa criminal conjunta extendida. Comparte los elementos de las anteriores, pues existe un plan común (que puede o no ser consecuencia de un aparato de represión) y la intención de la persona, que no comete materialmente el crimen, de participar del mismo. Sin embargo, la diferencia principal está en el elemento subjetivo (mens rea), pues, aunque los crímenes son cometidos más allá del plan común, son una “consecuencia natural y previsible del propósito común”. ${ }^{30}$

En el ECPI ya no se encuentra la empresa criminal conjunta, ${ }^{31}$ sin embargo, los redactores incorporaron varias figuras que implican la comisión conjunta o grupal de los crímenes de la competencia de la CPI. Basta un vistazo al artículo 25 para ver que se encuentra el "ordenar", ${ }^{32}$ figura que implica una relación de mando en un grupo u organización ${ }^{33}$ y la contribución a un grupo. $^{34}$

27 TPIY, Prosecutor v. Dusko Tadić, Judgment, Appeal Chamber, 15 June 1999, IT-94-1-A, párr. 196.

28 Ibidem, párr. 202 y 203.

29 TPIY, Prosecutor v. Simić, Tadić, Zarić, Judgment, Trial Chamber, 17 October 2003, IT-959-T, párr. 157.

30 TPIY, Prosecutor v. Kvocka et al., Judgment, Appeal Chamber, 28 February 2005, IT-9830/1-T, párr. 83.

31 Véase CPI, Prosecutor v. Thomas Lubanga Dyilo, Decision on the confirmation of charges, Pre-Trial Chamber I, 29 January 2007, ICC-01 /04-01 / 06-803, párr. 335. Hubo un rechazo a la empresa criminal conjunta en las conferencias de Roma, de lo contrario se hubiera incluido expresamente en el ECPI.

32 Véase ECPI, art. 25(3)(b).

33 Véase CPI, Prosecutor v. Sylvestre Mudacumura, Decision on the Prosecutor's Application under Article 58, Pre-Trial Chamber II, 13 July 2012, ICC-01/04-01/12-1-Red, párr. 63. El primer elemento objetivo es estar en una posición de autoridad, lo cual es imposible sin un grupo u organización.

34 Véase ECPI, art. 25(3)(d); véase CPI, Prosecutor v. Thomas Lubanga Dyilo, Judgment pursuant to article 74 of the Statute, Trial Chamber I, 14 March 2012, ICC-01/04-01/06-2842, párr. 996. "Both Articles 25(3)(a) and (d) address the situation in which a number of people are involved in a crime". Véase también CPI, Prosecutor v. William Samoei Ruto, Henry Kiprono Kosgey and Joshua Arap Sang, Decision on the Confirmation of Charges Pursuant to Article 61(7)(a) and (b) of the Rome Statute, Pre-Trial Chamber II, 23 January 2012, ICC-01/0901/11-373, párr. 351. Los elementos de la contribución al grupo son: debe haber un crimen competencia de la CPI que se comete (ya sea consumado o en grado de tentativa); un grupo 
Esta revista forma parte del acervo de la Biblioteca Jurídica Virtual del Instituto de Investigaciones Jurídicas de la UNAM

Por su parte, la responsabilidad del superior jerárquico, al igual que el "ordenar", implica una organización, que en el caso del jefe militar se traduce en el mando y control efectivo, o su autoridad y control efectivo. ${ }^{35}$ Asimismo, en el caso de los jefes no militares, se considera que son responsables por los crímenes "cometidos por subordinados bajo su autoridad y control efectivo". ${ }^{36}$

Aunque la CPI ha abandonado el empleo de la empresa criminal conjunta, la ha reemplazado como parte de su política criminal con las figuras de la coautoría y de la coautoría mediata, a través de aparatos organizados de poder (coautoría II), dependiendo de una interpretación del artículo 25 (3) (a) del ECPI. Lo interesante de estas figuras es que de la lectura del precepto no se desprende la comisión grupal: "Cometa ese crimen por sí solo, con otro o por conducto de otro, sea éste o no penalmente responsable”. ${ }^{37} \mathrm{Sin}$ embargo dicho elemento se ha incorporado jurisprudencialmente. La coautoría fue la forma de imputación y eventual condena en el caso Lubanga. Según lo establecido por la mayoría de la Sala de Primera Instancia I, la coautoría contiene dos elementos objetivos (actus reus): la existencia de un acuerdo o plan común entre dos o más personas con un elemento de criminalidad $^{38}$ y una contribución esencial de cada autor en la realización del crimen. ${ }^{39}$

de personas de conformidad con un plan común cometen el crimen; la contribución es distinta a las previstas en los incisos (a-c) del artículo 25 (3); la contribución fue intencional y con la finalidad de que el grupo lleve a cabo el crimen o con el conocimiento de que el grupo cometerá el crimen.

35 Véase ECPI, art. 28 (a); véase también CPI, Prosecutor v. Jean Pierre Bemba Gombo, Decision pursuant to Article 61 (7)(a) and (b) of the Rome Statute on the Charges of the Prosecutor Against Jean-Pierre Bemba Gombo, Pre-Trial Chamber II, 15 June 2009, ICC-01 / 05-01 / 08 424, párrs. 407, 408, 411, 413 y 415. El uso de términos como "control sobre fuerzas", "responsabilidad de mando sobre fuerzas armadas"y "cadena de mando" confirma que no solamente hay un grupo sino que debe estar altamente organizado.

36 Véase ECPI, art. 28(b).

37 Ibidem, art. 25(3)(a).

38 CPI, Prosecutor v. Thomas Lubanga Dyilo, Judgment pursuant to article 74 of the Statute, Trial Chamber I, 14 March 2012, ICC-01/04-01/06-2842, párr. 980. Cabe mencionar que dichos elementos han sido confirmados por la Sala de Apelaciones, sin embargo; debido a que la argumentación empleada para ello no es muy sustanciosa, para todos los fines sigue siendo vigente y aplicable la interpretación de la Sala de Primera Instancia. Véase, CPI, Prosecutor v. Thomas Lubanga Dyilo, Judgment on the appeal of Mr. Thomas Lubanga Dyilo against his conviction, Appeals Chamber, 1 December 2014, ICC-01/04-01/06-3121-Red, párrs. 469-473.

39 Ibidem, párr. 981. 
Esta revista forma parte del acervo de la Biblioteca Jurídica Virtual del Instituto de Investigaciones Jurídicas de la UNAM

En cuanto al elemento de criminalidad, la Sala determinó que si bien el acuerdo o plan no es necesariamente criminal, debe contener un elemento de criminalidad, es decir, por lo menos debe haber un riesgo de que un delito se pueda cometer en el curso natural de los acontecimientos. ${ }^{40}$ Por su parte, la contribución debe ser esencial como una forma de distinguir entre la autoría y otro tipo de auxilio que implique una mera complicidad y, en consecuencia, distinguir ente autores y partícipes. $^{41}$

Por lo que respecta al mens rea, la Sala de Primera Instancia I consideró que para la coautoría se deben satisfacer dos elementos, la persona debe de tener la intención $a$ ) de cometer el crimen y $b$ ) de proporcionar una contribución esencial para dicha comisión. ${ }^{42}$ Cabe resaltar que la Sala de Cuestiones Preliminares I reconoció otro elemento subjetivo que no fue señalado por la Sala de Primera Instancia I, pero que ha sido reconocido por otras instancias. Éste se refiere a que los coautores deben de estar conscientes y aceptar mutuamente que la implementación del plan común implicará la realización del actus reus del crimen. ${ }^{43}$

La coautoría II parte de la base de la coautoría, por lo que resulta evidente que al actus reus lo constituyan los mismos elementos de acuerdo con el caso Lubanga. De esta forma, en la confirmación de cargos del caso Katanga y Ngudjolo se retomó el actus reus ya establecido en la jurisprudencia de la CPI, ${ }^{44} \mathrm{y}$ pasó a analizar cómo ésta se puede ejercer mediante una organización.

El individuo debe tener control sobre la organización, ${ }^{45}$ lo cual se evidencia mediante la existencia de un aparato organizado y con una jerarquía establecida. Para ello es importante que haya pruebas del liderazgo y control que la persona imputada ejerce sobre sus subordinados, quienes cumplen sus órdenes de forma automática. ${ }^{46}$

40 Ibidem, párr. 984.

41 Ibidem, párr. 997.

42 Ibidem, párr. 1013.

43 Véase CPI, Prosecutor v. Thomas Lubanga Dyilo, Decision on the Confirmation of Charges, Pre-Trial Chamber I, 29 January 2007, ICC-01/04-01/06-803, párrs. 361-363; véase también CPI, Prosecutor v. Jean-Pierre Bemba Gombo, Decision pursuant to article 61(7)(a) and (b) of the Rome Statute on the Charges of the Prosecutor against Jean-Pierre Bemba Gombo, Pre-Trial Chamber II, 15 June 2009, ICC-01/05-01/08-424, párr. 351.

44 CPI, Prosecutor v. Germain Katanga and Ngudjolo Chui, Decision on the confirmation of charges, Pre-Trial Chamber I, 30 September 2008, ICC-01/04-01/07-717, párrs. 494, 519-539.

45 Ibidem, párrs. 500-510.

46 Ibidem, párr. 511-514. 
Esta revista forma parte del acervo de la Biblioteca Jurídica Virtual del Instituto de Investigaciones Jurídicas de la UNAM

De esta forma, se puede llegar a la conclusión de que las principales formas de autoría desde Núremberg implican la participación grupal en la comisión de los hechos. Hasta el momento solamente se ha dictado una confirmación de cargos por la autoría material y por inducir la comisión de crímenes de competencia de la CPI. Sin embargo, en el caso de la autoría material, se le imputa a Ntaganda una participación material, dentro del contexto de un ataque militar. ${ }^{47}$ En el caso de la inducción, esta forma de imputación se presentó como una alternativa al "ordenar" y se dio por probada con los mismos elementos. ${ }^{48}$

El caso Ntaganda evidencia lo que dice el propio texto del ECPI, que hay formas de imputación que no necesariamente implican la responsabilidad grupal de las personas. Pero también permite señalar que aun cuando la responsabilidad no es grupal, ésta se da en un contexto de violencia masiva, como ya se mencionó en este apartado. Los argumentos aquí vertidos deben tomarse en conjunto con dicho principio de DPI.

\section{CULPABILIDAD}

El concepto de culpabilidad es propio de los sistemas penales liberales y occidentales, no obstante no parece haber una coincidencia en las definiciones y contenido de la misma. Sin embargo, según Ferrajoli, se pueden distinguir tres elementos en cada una de las posturas de la dogmática penal moderna: a) la vinculación entre la decisión del sujeto, la acción y el resultado; b) la capacidad del sujeto de entender y querer la conducta, y c) la concreta consciencia y voluntad de cometer el delito. ${ }^{49}$

47 Véase CPI, Prosecutor v. Bosco Ntaganda, Decision Pursuant to article 61(7)(a) and (b) of the Rome Statute on the Charges of the Prosecutor against Bosco Ntaganda, Pre-Trial Chamber II, 9 June 2014, ICC-01 /04-02/06-309, párrs. 137-143.

48 Ibidem, párrs. 154-157.

49 Véase Ferrajoli, Luigi, Derecho y razón. Teoría del garantismo penal, 5a. ed., Madrid, Trotta, 2001, pp. 489 y 490. Resulta también interesante que este autor desprende estos elementos del Schuld alemán y del mens rea anglosajón cuando normalmente se considera que son formas diferentes de entender la culpabilidad. Esto es importante dado que en el common law este concepto (culpability) se equipara a la existencia de un elemento subjetivo, por mínimo que sea; mientras que en la dogmática penal alemana (aunque no hay unanimidad) se puede equiparar con la posibilidad de reprochar la conducta). Así, esta definición supera las discrepancias terminológicas de ambas familias jurídicas al proponer una síntesis de ambas. 
Esta revista forma parte del acervo de la Biblioteca Jurídica Virtual del Instituto de Investigaciones Jurídicas de la UNAM

La base de la culpabilidad está en el libre albedrío, pues para establecerla será necesario determinar si el sujeto pudo haber actuado de otra manera. ${ }^{50}$ Por lo tanto, la culpabilidad es una figura que no puede responder a las condiciones del individuo, sino al delito, como presupuesto de la sanción penal. Consecuentemente, la culpabilidad queda excluida cuando el sujeto no tuvo más alternativa que la concreción de los elementos típicos. ${ }^{51}$

Si se adopta esta postura, para encontrar elementos de culpabilidad en el DPI se deben buscar disposiciones que individualicen la responsabilidad penal; es decir, que se sancione al individuo por sus acciones. Esto sería contrario a lo que se presentó en Núremberg, donde la pertenencia a una organización criminal era ya considerada un crimen. Como complemento a lo anterior, y con base en el libre albedrío, sería necesario que solamente se sancionara a las personas que tuvieron oportunidad de hacer un juicio de valor sobre su conducta; en otras palabras, que pudieron elegir entre realizar la conducta o no.

La postura de Núremberg fue superada por el TPIY ya que en la sentencia de apelación en el caso Tadic se estableció por primera vez la culpabilidad como parte del DPI, ${ }^{52}$ mediante el reconocimiento irreductible de una conducta (actus reus) y un elemento subjetivo de la responsabilidad: "La presunción básica debe de ser que en el derecho internacional, así como en los sistemas nacionales, el fundamento de la responsabilidad penal es el principio de culpabilidad personal: nadie puede ser declarado penalmente responsable por actos o transacciones de las que no estuvo involucrado personalmente o de alguna manera haya participado (nulla poena sine culpa)". ${ }^{53}$

50 Ibidem, 493; véase también Bock, Stephanie, “The Prerequisite of Personal Guilt”, Utrecht Law Review, vol. 9, núm. 4, September 2013, pp. 184-186. El concepto de responsabilidad individual tiene dos elementos básicos: la relación psicológica entre el autor y el acto y el reproche moral (moral blameworthiness).

51 Ibidem, p. 503.

52 No obstante esta afirmación el Principio IV de Núremberg señala textualmente "El hecho de que una persona haya actuado en cumplimiento de una orden de su gobierno o de un superior jerárquico no la exime de responsabilidad conforme al derecho internacional, si efectivamente ha tenido la posibilidad moral de opción (moral choice)". La mención a la alternativa para no actuar conforme a las órdenes del superior jerárquico podría ser considerado un antecedente remoto de la culpabilidad en el DPI.

53 TPIY, Prosecutor v. Dusko Tadić, Judgment, Appeals Chamber, 15 June 1999, IT-94-1-A, párr. 186. "The basic assumption must be that in international law as much as in national systems, the foundation of criminal responsibility is the principle of personal culpability: nobody 
Esta revista forma parte del acervo de la Biblioteca Jurídica Virtual del Instituto de Investigaciones Jurídicas de la UNAM

Sin embargo, cabe la siguiente pregunta: ¿hay un reconocimiento de la culpabilidad en el DPI actual? El cuestionamiento es válido dado que no se volvió a mencionar la culpabilidad en los tribunales ad hoc. Aunque tampoco hay una mención expresa en el ECPI, existen suficientes elementos para pensar que su reconocimiento es tácito. Para ello se pueden analizar los siguientes preceptos.

En primer lugar está el artículo 25(2) que establece: "Quien cometa un crimen de la competencia de la Corte será responsable individualmente y podrá ser penado de conformidad con el presente Estatuto.” Así, este precepto establece la base de la culpabilidad que es la responsabilidad penal individual. Esto es importante dado que se tendría que excluir cualquier forma de responsabilidad que implique la mera pertenencia a un grupo o condiciones personales. ${ }^{54}$

En este contexto ha sido poco estudiado el artículo 25(3)(d) que señala que será penalmente responsable quien:

Contribuya de algún otro modo en la comisión o tentativa de comisión del crimen por un grupo de personas que tengan una finalidad común. La contribución deberá ser intencional y se hará:

i) Con el propósito de llevar a cabo la actividad o propósito delictivo del grupo, cuando una u otro entrañe la comisión de un crimen de la competencia de la Corte; o

ii) $A$ sabiendas de que el grupo tiene la intención de cometer el crimen. ${ }^{55}$

Un cuidadoso análisis de este precepto permite notar que se trata de los mismos elementos de la empresa criminal conjunta; pero se le han incorporado elementos subjetivos que antes estaban ausentes o era dudosa su existencia, lo que generó que un sector de la doctrina considerara que se trataba, pre-

may be held criminally responsible for acts or transactions in which he has not personally engaged or in some other way participated (nulla poena sine culpa)".

54 Véase Gil Gil, Alicia y Maculan, Ana Elena, "Current Trends in the Definition of «Perpetrator» by the International Criminal Court: From the Decision on the Confirmation of Charges in the Lubanga case to the Katanga judgment”, Leiden Journal of International Law, vol. 28, 2015, pp. 361 y 362. La interpretación de la coautoría en el caso Lubanga se aproxima a una responsabilidad por ser líder de un grupo al reducir considerablemente el conocimiento de las conductas ilícitas de los subordinados.

55 Cursivas del autor. 
Esta revista forma parte del acervo de la Biblioteca Jurídica Virtual del Instituto de Investigaciones Jurídicas de la UNAM http://www.juridicas.unam.mx/ https://biblio.juridicas.unam.mx/bjv https://revistas.juridicas.unam.mx/ DOI: http://dx.doi.org/10.22201/iij.24487872e.2018.18.12107

cisamente, de un desconocimiento de la culpabilidad. ${ }^{56}$ Esta situación ya se corrigió en el ECPI, lo cual resulta interesante, pues es un ajuste hecho por los redactores que implica reconocer el elemento volitivo de la culpabilidad. ${ }^{57}$ Esto se confirma con el artículo 30(1) del Estatuto que señala que "una persona será penalmente responsable y podrá ser penada por un crimen de la competencia de la Corte únicamente si los elementos materiales del crimen se realizan con intención y conocimiento de los elementos materiales del crimen".

Sin embargo, es más interesante que el mismo precepto señala que la intención implica que la persona se proponga incurrir en la conducta criminal y causar una consecuencia. ${ }^{58}$

Esta frase es importante porque está relacionada ya no sólo con el elemento subjetivo de la culpabilidad; sino directamente con el tercer punto señalado por Ferrajoli. Así, se puede afirmar que no sólo en el ECPI se reconoce la culpabilidad sino que la misma tiene un significado garantista, como el propuesto por Ferrajoli. Estas afirmaciones encuentran su correlativo en el artículo 31 de este tratado internacional, ya que se establecen diversas hipótesis normativas que eximen de la responsabilidad cuando la persona no está en posibilidades de realizar libremente la conducta criminal..$^{59}$

56 Véase Gil Gil, Alicia, "Principales figuras de imputación a título de autor en derecho penal internacional: empresa criminal conjunta, coautoría por dominio funcional y coautoría mediata", Cuadernos de Política Criminal, núm. 109, Época II, mayo de 2013, pp. 117 y 118.

57 Dondé Matute, Javier, "Reflexiones sobre la empresa criminal común, la coautoría y las formas de imputación del Estatuto de la Corte Penal Internacional desde la política criminal”, en Guevara Bermúdez, José y Dondé Matute, Javier (coords.), Ensayos sobre temas selectos de la Corte Penal Internacional, México, Inacipe-Universidad Autónoma de Tlaxcala-Tiran Lo Blanch, 2016, pp. 81-86. En este apartado se explica la naturaleza entre la empresa criminal conjunta y las formas de autoría del ECPI.

58 Véase ECPI, art. 30(2)(a-b) A los efectos del presente artículo, se entiende que actúa intencionalmente quien: a) en relación con una conducta, se propone incurrir en ella, o $b$ ) en relación con una consecuencia, se propone causarla o es consciente de que se producirá en el curso normal de los acontecimientos.

59 Véase ECPI, art. 31(1)(d): Hubiere incurrido en una conducta que presuntamente constituya un crimen de la competencia de la Corte como consecuencia de coacción dimanante de una amenaza de muerte inminente o de lesiones corporales graves continuadas o inminentes para él u otra persona, y en que se vea compelido a actuar necesaria y razonablemente para evitar esa amenaza, siempre que no tuviera la intención de causar un daño mayor que el que se proponía evitar. Esa amenaza podrá: i) haber sido hecha por otras personas; o ii) estar constituida por otras circunstancias ajenas a su control. 
Esta revista forma parte del acervo de la Biblioteca Jurídica Virtual del Instituto de Investigaciones Jurídicas de la UNAM

Otra forma de identificar la culpabilidad se encuentra en la introducción general a los elementos de los crímenes: "Con respecto a los elementos de intencionalidad relacionados con elementos que entrañan juicios de valor, como los que emplean los términos «inhumanos»o «graves», por ejemplo, no es necesario que el autor haya procedido personalmente a hacer un determinado juicio de valor, a menos que se indique otra cosa" ${ }^{60}$

Este párrafo señala que hay diversos juicios de valor que tiene que hacer el individuo para ser considerado penalmente responsable. Lo que esta nota interpretativa hace es establecer excepciones a la regla general. Ahora bien, en la medida en la cual la culpabilidad implica estar en posibilidades de hacer un juicio de valor, entonces, a contrario sensu, puede desprenderse que todos los demás elementos típicos implican un juicio de valor. Esta conclusión, además es compatible con el artículo 30 del ECPI, que exige que el individuo se proponga, es decir, pondere la comisión criminal.

Hay otra forma de fundamentar el reconocimiento tácito de la culpabilidad. El artículo 22 del ECPI establece el principio de legalidad penal. Este precepto debe ser interpretado de conformidad con los derechos humanos internacionalmente reconocidos. En particular, es importante transcribir el artículo 22(1): "Nadie será penalmente responsable de conformidad con el presente Estatuto a menos que la conducta de que se trate constituya, en el momento en que tiene lugar, un crimen de la competencia de la Corte". ${ }^{61}$

La primera observación importante es que se utiliza la palabra "conducta”, lo cual implica, en consonancia con la culpabilidad, que se sancionarán acciones u omisiones, no condiciones personales del individuo. En este sentido, la Corte Interamericana de Derechos Humanos (Corte IDH) ha desprendido la culpabilidad del reconocimiento expreso del principio de legalidad penal al prohibir los criterios peligrosistas o de derecho penal de autor:

La valoración de la peligrosidad del agente implica la apreciación del juzgador acerca de las probabilidades de que el imputado cometa hechos delictuosos en el futuro, es decir, agrega a la imputación por los hechos realizados, la previsión de hechos futuros que probablemente ocurrirán. Con esta base se despliega la fun-

60 Elementos de los crímenes, introducción general, párr. 4.

61 Cursivas del autor. 
Esta revista forma parte del acervo de la Biblioteca Jurídica Virtual del Instituto de Investigaciones Jurídicas de la UNAM

ción penal del Estado. En fin de cuentas, se sancionaría al individuo — con pena de muerte inclusive - no con apoyo en lo que ha hecho, sino en lo que es. Sobra ponderar las implicaciones, que son evidentes, de este retorno al pasado, absolutamente inaceptable desde la perspectiva de los derechos humanos. El pronóstico será efectuado, en el mejor de los casos, a partir del diagnóstico ofrecido por una pericia psicológica o psiquiátrica del imputado. ${ }^{62}$

Consecuentemente, la culpabilidad está reconocida también en función de una interpretación pro persona como ordena el artículo 21(3) del ECPI.

No obstante estos argumentos, un sector amplio de la doctrina considera que la responsabilidad grupal y la culpabilidad son incompatibles. ${ }^{63}$ Esta apreciación deriva principalmente de la idea de que figuras como la empresa criminal conjunta y la coautoría mediata, a través de aparatos organizados de poder, anteponen el grupo al individuo en la imputación. Sin embargo, eventos como el caso Ntaganda ilustran que si bien hay una prevalencia para utilizar estas formas grupales de imputación, lo que acontece es que la responsabilidad individual se da en un contexto grupal. Reconocer que hay un grupo detrás de cada conducta criminal individual no implica más que establecer el contexto en el que se dan estos crímenes internacionales. Ésta es la forma en la que se desarrolla la responsabilidad penal internacional y el DPI.

Lo que aquí se propone implica reconocer que si bien la responsabilidad es individual y sujeta a los juicios de valor propios del respeto a la culpabilidad, estas conductas no se realizan de forma aislada. ${ }^{64}$ La afirmación más novedosa que se hace aquí es que sin el reconocimiento de la existencia de un grupo al que pertenece el individuo o, al que auxilia sin pertenecer, no puede haber responsabilidad penal internacional.

62 Corte IDH, Caso Fermín Ramírez v. Guatemala, Fondo, reparaciones y costas. Sentencia del 20 de junio de 2005, Serie C, núm. 126, párr. 95.

63 Véase Fletcher, George P., "The Storrs Lectures: Liberals and Romantics at War: The Problem of Collective Guilt”, The Yale Law Journal, vol. 111, 2002. Este autor propone un concepto de culpabilidad colectiva que implica que toda una nación puede ser reprochada por la comisión de crímenes internacionales.

64 Véase Drumbl, Mark A., op. cit., pp. 32 y 33 (las redes de complicidad en el DPI son más complejas que las que se dan en los delitos nacionales o transnacionales; incluso aquellas de carácter colectivo como la delincuencia organizada). 
Esta revista forma parte del acervo de la Biblioteca Jurídica Virtual del Instituto de Investigaciones Jurídicas de la UNAM

\section{NORMAS DE INTERPRETACIÓN}

Como se anunció en la introducción de este trabajo, el DPI tiene sus propias reglas de interpretación. En particular el artículo 22(2) que establece la interpretación estricta de la ley penal y lo que se puede describir como la expresión del principio pro persona en el DPI previsto en el artículo 21(3). Estas reglas de interpretación distinguen al DPI del derecho internacional general, dado que son aplicables cuando está de por medio la responsabilidad de las personas, más no la de los Estados. No obstante, estas reglas surgen del derecho internacional de los derechos humanos, por lo que no le son exclusivas al DPI. También están presentes en el derecho penal nacional, como parte de la recepción de los derechos humanos ${ }^{65}$ o como una expresión del principio de legalidad penal. ${ }^{66}$ Sin embargo, sí son elementos de distinción con el derecho internacional general. En efecto, derivado de la responsabilidad penal internacional, las reglas de interpretación deben de corresponder a las previstas como límites al poder punitivo y deben ser coincidentes con los derechos humanos.

Así las cosas, la conclusión a la que se llega en este apartado es que estos dos cánones de interpretación no representan la expresión de un (meta)lenguaje del DPI. No significa que el DPI no tenga su propio (meta)lenguaje, solamente que sus reglas de interpretación no lo evidencian.

Resulta importante hacer una mención, aunque sea breve, de las normas de interpretación, no porque sean un elemento de la responsabilidad penal internacional, sino porque son una consecuencia de que la responsabilidad sea individual. No solamente el acento en los elementos subjetivos y la culpabilidad son importantes cuando el individuo está de por medio, sino también la manera en la cual se deberá interpretar el derecho. Dicho de otra manera, si la responsabilidad penal internacional no fuera individual no serían necesarias estas disposiciones del ECPI. Por lo tanto, se confirma el carácter individual de esta responsabilidad y sus componentes.

65 Véase Constitución Política de los Estados Unidos Mexicanos, art. 1, párrafo 2.

$66 \mathrm{Al}$ respecto véase Dondé Matute, Javier, Principio de legalidad penal. Perspectivas de derecho nacional e internacional, 2a. ed., México, Porrúa, 2010, pp. 208 y 209. Evidenciando que esta regla de interpretación (lex stricta) está presente en diversos sistemas jurídicos del mundo. 
Esta revista forma parte del acervo de la Biblioteca Jurídica Virtual del Instituto de Investigaciones Jurídicas de la UNAM

\section{CONCLUSIÓN}

La responsabilidad penal internacional es un principio del DPI, que además tiene la característica de ser su principio fundador e histórico. Sus primeras características se pueden observar de la distinción con la responsabilidad estatal y la responsabilidad penal nacional. Este principio se reconoce como internacional pues parte de la protección de bienes jurídicos en el ámbito internacional y tiene su fundamento en normas jurídicas internacionales. Puede decirse que éstos son sus elementos material y formal, respectivamente. La responsabilidad penal internacional parte de la existencia de un elemento subjetivo (mens rea), a diferencia de lo que ocurre con la responsabilidad estatal. Pero puede decirse que se va más allá, pues también se reconoce la culpabilidad como uno de sus elementos, entendida como el juicio de valor que realiza la persona al cometer una conducta delictiva.

Esto se ha comprobado con el abandono formal en la sentencia de apelación de Tadic y su reconocimiento tácito en el ECPI. Como se vio, hay una gran cantidad de preceptos aislados que hacen alusión a la culpabilidad como la imputación individual (art. 25.1), por una conducta (art. 22.1) cometida con elementos subjetivos mínimos (art. 25.3.d y art. 30.1) que impliquen la posibilidad de realizar un juicio de valor (art. 30.2, Elementos de los crímenes, introducción general, párrafo 4). Tomados en su conjunto y auxiliados por la interpretación del principio de legalidad del sistema interamericano, resulta que hay un reconocimiento de la culpabilidad garantista en la regulación de la responsabilidad penal internacional en el ECPI.

En conclusión, se define la responsabilidad penal internacional como la posibilidad de sancionar a las personas por violaciones al derecho internacional (conforme a los criterios de distinción formal y material), que tiene como elementos una conducta (actus reus) cometida con intención (mens rea) y con base en un juicio de valor (culpabilidad), siempre en un contexto grupal. 
Esta revista forma parte del acervo de la Biblioteca Jurídica Virtual del Instituto de Investigaciones Jurídicas de la UNAM

\section{BibliogRAFÍA}

Ambos, Kai, Fundamentos de la imputación en el derecho internacional penal, México, Porrúa, 2009.

BASsiouni, Cherif M., Crimes against humanity in International Criminal Law, 2a. ed., La Haya, Kluwer Law International, 1999.

Bock, Stephanie, “The Prerequisite of Personal Guilt”, Utrecht Law Review, vol. 9, núm. 4, September 2013.

DONDÉ MATUTE, Javier, Fuentes del derecho penal internacional. Ensayos para el desarrollo del sistema de justicia internacional, México, Porrúa, 2015.

Dondé MatuTe, Javier, Principios de Núremberg: desarrollo y actualidad, México, Inacipe, 2015.

Dondé Matute, Javier, Principio de legalidad penal. Perspectivas de derecho nacional e internacional, 2a. ed., México, Porrúa, 2010

Dondé MATUTE, Javier, Tipos penales en el ámbito internacional, 2a. ed., México, Inacipe, 2012.

DondÉ MATUTE, Javier, "Reflexiones sobre la empresa criminal común, la coautoría y las formas de imputación del Estatuto de la Corte Penal Internacional desde la Política Criminal”, en GUEVARA BERMúdeZ, José y Dondé MATUTE, Javier (coords.), Ensayos sobre temas selectos de la Corte Penal Internacional, México, Inacipe-Universidad Autónoma de TlaxcalaTiran Lo Blanch, 2016.

Drumbl, Mark A., "Collective Violence and Individual Punishment: The Criminality of Mass Atrocity", Northwestern University Law Review, vol. 99, núm. 2, 2005.

FERRAJOLI, Luigi, Derecho y razón. Teoría del garantismo penal, 5a. ed., Madrid, Trotta, 2001.

Fletcher, George P., "Collective Guilt and Collective Punishment", Theoretical Inquiries, vol. 5, 2004.

FlETCHER, George P., "The Storrs Lectures: Liberals and Romantics at War: The Problem of Collective Guilt", TheYale Law Journal, vol. 111, 2002.

Gil GIL, Alicia, "Principales figuras de imputación a título de autor en derecho penal internacional: empresa criminal conjunta, coautoría por dominio funcional y coautoría mediata", Cuadernos de Política Criminal, núm. 109, época II, mayo de 2013. 
Esta revista forma parte del acervo de la Biblioteca Jurídica Virtual del Instituto de Investigaciones Jurídicas de la UNAM

GIL GIL, Alicia y MaCulan, Ana Elena, "CurrentTrends in the Definition of «Perpetrator» by the International Criminal Court: From the Decision on the Confirmation of Charges in the Lubanga case to the Katanga judgment”, Leiden Journal of International Law, vol. 28, 2015.

GREPPI, Edoardo, "La evolución de la responsabilidad penal individual bajo el derecho internacional”, Revista Internacional de la Cruz Roja, núm. 835, 1999, disponible en: www.icrc.org/web/spa/sitespa0.nsf/htmlall/5tdnnf?open document.

Herdegen, Matthias, Derecho internacional público, trad. de Marcela Anzola, México, UNAM-Fundación Konrad Adenauer, 2005.

OHLIN, Jens David, “Co-Perpetration German Dogmatik or German Invasion?", The Law and Practice of the International Criminal Court:A Critical Account of Challenges and Achievements, Cornell Legal Studies Research Paper No. 14-07, 2015.

OSIEL, Mark, "Banality of Good: Aligning Incentives against Mass Atrocity", Columbia Law Review, vol. 105, 2005.

Ratner, Steven R. y Abrams, Jason S., Accountability for Human Rights Atrocities in International Law. Beyond the Nuremberg Legacy, 2a. ed., Nueva York, Oxford University Press, 2001.

Robinson, Darryl, "International Criminal Law as Justice”, Journal of International Criminal Justice, vol. 11, septiembre de 2013.

SHAw, Malcolm N., International Law, 5a. ed., Reino Unido, Oxford University Press, 2003.

StePHEns, Pamela J., "Collective Criminality and Individual Responsibility: The Constraints of Interpretation”, Vermont Law School Paper, núm. 1014, 2014.

\section{Jurisprudencia}

CIJ, Case Concerning the Application of the Convention on the Prevention and Punishment of the Crime of Genocide (Bosnia-Herzegovina v. Serbia and Montenegro), Judgment, I.C.J. Reports 2007, p. 43, 26 February 2007.

CIJ, Case Concerning the Application of the Convention on the Prevention and Punishment of the Crime of Genocide (Bosnia-Herzegovina v. Yugosla- 
Esta revista forma parte del acervo de la Biblioteca Jurídica Virtual del Instituto de Investigaciones Jurídicas de la UNAM

via), Preliminary Objections, Judgment, I.C.J. Reports 1996, p. 595, 11 July 1996.

CIJ, Case Concerning the Application of the Convention on the Prevention and Punishment of the Crime of Genocide (Croatia v. Serbia), Judgment, 3 February 2015.

CORTE IDH, Caso Fermín Ramírez v. Guatemala, Fondo, reparaciones y costas. Sentencia del 20 de junio de 2005, Serie C, núm. 126.

CPI, Prosecutor v. Bemba Gombo, Decision pursuant to Article 61(7)(a) and (b) of the Rome Statute on the Charges of the Prosecutor Against JeanPierre Bemba Gombo, Pre-Trial Chamber II, 15 June 2009, ICC-01 / 05 01/08-424.

CPI, Prosecutor v. Lubanga, Decision on the confirmation of charges, PreTrial Chamber I, 29 January 2007, ICC-01/04-01/06-803.

CPI, Prosecutor v. Lubanga, Judgment pursuant to article 74 of the Statute, Trial Chamber I, 14 March 2012, ICC-01/04-01/06-2842.

CPI, Prosecutor v. Lubanga, Judgment on the appeal of Mr. Thomas Lubanga Dyilo against his conviction, Appeals Chamber, 1 December 2014, ICC01/04-01/06-3121-Red.

CPI, Prosecutor v. Mudacumura, Decision on the Prosecutor's Application under Article 58, Pre-Trial Chamber II, 13 July 2012, ICC-01/04-01/121-Red.

CPI, Prosecutor v. Ntaganda, Decision Pursuant to article 61(7)(a) and (b) of the Rome Statute on the Charges of the Prosecutor against Bosco Ntaganda, Pre-Trial Chamber II, CPI, 9 June 2014, ICC-01/04-02/06-309. CPI, Prosecutor v. Ruto, Kosgey and Sang, Decision on the Confirmation of Charges Pursuant to Article 61(7)(a) and (b) of the Rome Statute, PreTrial Chamber II, 23 January 2012, ICC-01/09-01/11-373.

TPIY, Prosecutor v. Kvocka et al., Judgment, Appeal Chamber, 28 February 2005, IT-98-30/1-T.

TPIY, Prosecutor v. Simic, Tadic, Zaric, Judgment, Trial Chamber, 17 October 2003, IT-95-9-T.

TPIY, Prosecutor v. Tadic, Judgment, Appeal Chamber, 15 June 1999, IT-9 4-1-A.

Tribunal Militar Internacional de Núremberg, Judgment in the Trial of German MajorWar Criminals, 1 de octubre de 1946. 
Esta revista forma parte del acervo de la Biblioteca Jurídica Virtual del Instituto de Investigaciones Jurídicas de la UNAM http://www.juridicas.unam.mx/

2. Legislación nacional e internacional

Carta del Tribunal de Núremberg.

Constitución Política de los Estados Unidos Mexicanos.

Convención de los Derechos del Niño.

Draft articles on Responsibility of States for Internationally Wrongful Acts, with commentaries.

Estatuto de la Corte Penal Internacional. 